\title{
Valenţele pastoral-misionare ale bioeticii ortodoxe contemporane
}

\author{
Cosmin LAZĂR*
}

Abstract: Bioethics was born in the United States in the 1970's as an urgent necessity, aimed at meeting the challenges of its time. These challenges were seen as being so threatening to humanity, that the American oncologist Van Rensselaer Potter, who coined the term bioethics, called it "the science of survival". Today we can observe two types of bioethical models, based on clear-cut differences between orthodox Christian views, particularly those about life, and secularized views. Accordingly, two distinct currents are generated: the Christian moral system, and the secular ethical system. Secular, or social, bioethics, deeply anchored in contemporary secularism, avoids religious and moral beliefs, advocating the progress of bio-technologies with applicability to human nature, and accepting moral relativism. These challenges, of an ethical and moral nature, require Christian Orthodox bioethics to adopt a position joining the ecclesial, spiritual, and pastoral experience with the reflections and

\footnotetext{
"PhD Candidate, Faculty of Orthodox Theology at "1 Decembrie 1918" University in Alba Iulia, Romania.
} 


\section{Cosmin LAZĂR}

proposals of biologists. The Christian perspective in bioethics implies abandoning the distant concepts grounded only in the common good and mutual interest, and taking roots firmly in the recognition and experience of a transcendent God and in a morality with a full content.

Key words: secular bioethics, quality of life, authonomy principle, utilitarianism, sanctity of life.

\section{Etică şi relativism moral în reperele şi provocările bioeticii seculare}

Societatea contemporană secularizată şi globalizantă ne descoperă tipologia omului postmodern care refuză tot mai mult în a se prosterna în faţa Raţiunii Creatorului, înălţându-şi altare propriei raţiuni, cu ajutorul cărora încearcă să devină el însuşi stăpân absolut al Universului.

Plămădită din interferenţa a două cunoaşteri, cea biologică, a fiinţei percepută ca existenţă organică şi cea etică, înţeleasă ca sistem de norme şi principii morale care definesc valoarea fiinţei umane, din punct de vedere conceptual ,bioetica” însumează o arie semantică foarte extinsă, aspect dovedit de multitudinea şi diversitatea definiţiilor pe care le-a primit. Deşi mediile ştiinţifice internaţionale, şi în mod special cele americane, îl consideră pe Van Rensselaer ca fiind primul care a utilizat şi apoi conceptualizat acest termen în anul 1970, totuşi pastorul şi filozoful german protestant Fritz Jahr a redactat în anul 1927, în revista germană „Kosmos”, un inovator şi original articol intitulat ,Bio-Ethik. Eine Umschau über die ethischen Bezeihungen des Menschen zu Tier und Pflanze" 2 în care utilizează acest termen. În acest sens el precizează că ,,regulile pentru acţiunile noastre ar putea fi cerinţe de natură bio-etică: respectarea fiecărei fiinţe vii de pe principiul scopului în sine şi tratarea ei, daca este posibil, ca atare"3.

${ }^{2}$ „Bio-etica.Un tur de orizont al relaţiilor etice între oameni, plante şi animale”. ${ }^{3}$ Fritz Jahr, Aufzätze zur Bioethik 1924-1948, Münster, Lit Verlag, 2013, pp. 25-26. 
Bioetica adresează oamenilor de ştiinţă dar şi fiecărei persoane, responsabilă şi conştientă de dimensiunea creştină a propriei sale existenţe precum şi a semenului, întrebarea fundamentală: care sunt valorile morale şi spirituale care constituie firul roşu călăuzitor pentru noi, creştinii mileniului III, în contextul provocărilor biotehnologice contemporane?

Relativismul generează un nou tip de gândire conform căreia ceea ce este valabil pentru propria persoană nu este în mod obligatoriu valabil şi pentru semenul său, în condiţiile în care nu există nici o instanţă sau o autoritate obiectivă şi incontestabilă care să interzică acest lucru. Ceea ce omul a construit spiritual până acum, acelaşi om, dar parcă cu totul altul, neagă cu vehemenţă. Se poate observa aici un aspect evident: s-a încheiat etapa normelor externe cu Trascendentul, cu autoritatea Divinităţii, datoriile sociale devenind utilitariste, cele familiale superficiale, iar despre cele comunitare vorbindu-se la trecut.

Bioetica suferă şi ea influenţele curentelor religioase şi morale şi este important ca acestea să fie identificate pentru a stabili modalitatea prin care gândirea omului le acceptă şi pentru a se putea identifica în funcţie de acestea care sunt valenţele pastorale şi misionare pe care Biserica şi creştinismul le poate pune la dispoziţie, în vederea promovării unei bioetici ortodoxe cu un conţinut moral adecvat $t^{4}$.

Autonomia umană reprezintă una dintre efectele cele mai serioase ale relativismului moral, pentru că prin ,,autonomizarea umanului", fiinţa umană este tehnologizată în mod excesiv. În fapt, se afirmă libertatea umană, prin acceptarea raţiunii ca fiind singurul reper necesar instituirii unei societăţi care poate duce la fericirea individului. Această autonomie se extinde şi la elementul divin, concretizânduse în individualism religios, social şi cultural, puternic generator de numeroase derapaje morale, în care biotehnologizarea umanului pare

\footnotetext{
${ }^{4}$ Thomas J., Bole III, The person in secular and in orthodox-catholic bioethics,în „Christian Bioethics”, 2000, 6 (1), pp. 86-90.
} 
a fi un imperativ ${ }^{5}$. Un alt element este reprezentat de ,,individualizarea comportamentului moral", în care morala este centrată pe individ şi pe voinţa lui, cu scopul de a nu-i fi lezate drepturile şi libertăţile sale, cerinţe care nu vizează nimic altceva decât binele individual. Totul îi este permis omului postmodern pentru a-şi putea dezvolta fără constrângeri personalitatea, convertită de fapt în individualitate. De aceea astăzi valorile care se promovează la nivel individual sunt cu prioritate cele preferate de individ, valori din care sunt absente conotaţiile religioase sau cele comunitare. Principalele surse pentru justificarea unor acţiuni neacceptate sunt „libertinajul moral” şi ,permisivitatea morală”. Postmodernitatea are tendinţa de a îndeplini visul uman etern al dispariţiei normelor, regulilor şi atitudinilor morale creştine. Desprinzându-se de libertatea în Dumnezeu, omul resimte orice limită mai degrabă ca pe o îngrădire a personalităţii sale decât ca pe o şansă de întărire şi creştere spirituală ${ }^{6}$. „,Ambiguitatea”, ca factor al relativismului moral, introduce în sfera vieţii religioase incertitudinea care duce la dispariţia reperelor religioase şi apariţia elementelor sincretiste.

In mod paradoxal spiritul moralei este afirmat pretutindeni, este invocat permanent, totul primind o conotaţie etică, în afacere, în instituţiile publice sau în viaţa de familie. Pe de altă parte, la nivel practic imoralitatea şi acţiunile reprobabile săvârşite în mod individual sau colectiv cresc alarmant. „Relativizarea relaţiei cu aproapele” şi cu ,sinele” sunt rezultatul comportamentului preponderent individualist şi egoist al omului contemporan, care îl îndepărtează pe semenul său din atenţie şi îl aşează într-un plan secund7.

${ }^{5}$ Charles Rubin, Human Dignity and future of Man, în Adam Schulman, Thomas W. Merrill, „Human Dignity and Bioethics. Essays Commissioned by the President's Council on Bioethics", Washington, D. C., Washington University Press, 2008, pp. 155-173.

${ }^{6} \mathrm{H}$. Tristram JR. Engelhardt, Sin and bioethic: why a liturgical anthropology is foundational, în „Christian Bioethics”, 2005, 11 (3), pp. 221-239.

${ }^{7}$ Georgios Mantzarides , Globalization and universality: chimera and truth, în 
Omul postmodern se află în postura de a se căuta pe sine însuşi, uitând de unde a plecat şi unde se poate regăsi din nou, din cauza faptului că ,,accentuarea raţionalistă a existenţei sale 1-a făcut să-şi uite rădăcinile, individualismul - să se închidă comunicării duhovniceşti profunde cu semenii şi cu natura şi să se raporteze moral prin faptă la divinitate iar noul materialism şi tehnicismul - să se mintă, spunându-şi că scopul existenţei este... el însuşiı"

\section{Liberalismul, utilitarismul şi materialismul în contextul biotehnologiilor contemporane}

Apariţia bioeticii seculare ca domeniu academic şi fundament pentru politicile publice de asistenţă medicală a fost una dintre cele mai dramatice evoluţii culturale a lumii postbelice. $\mathrm{Cu}$ această perioadă s-a înregistrat un interes tot mai crescut atât în ceea ce priveşte etica medicală dar şi în dezvoltarea ştiinţelor medicale biotehnologice.

\section{Liberalismul radical}

Această perspectivă pleacă de la premiza faptului că nu există un mod de cunoaştere a unui adevăr obiectiv comun şi coincide pe plan teoretic cu pluralismul bioetic înţeles nu doar ca o considerare factuală a pluralităţii de etici ci şi ca o afirmare a ireductibilităţii acestora99. Pluralitatea viziunilor morale, care stau la baza postmodernităţii, reprezintă fără îndoială o provocare serioasă la adresa moralei contemporane. Elementele sau dimensiunile moralei nu pot fi integrate în această viziune secularistă. Orice viziune etică subiectivă este acceptată pasiv. Cu alte cuvinte, morala nu se întemeiază pe fapte, nici pe valori morale sau transcendente, ci pe aplicarea automomă a individului. Deoarece fiecare acţionează în conformitate cu libertatea

\footnotetext{
„Christian Bioethics”, 2002, 8 (2), pp. 199-207.

${ }^{8}$ Ştefan Iloaie, op. cit., p. 174.

${ }^{9}$ Sharon Tamar, Human nature in an age of biotechnology, Dordrecht, Springer Netherlands, 2014, p. 33.
} 
sa de conştiinţă, avem de a face cu un subiectivism radical şi cu un relativism moral nelimitat ${ }^{10}$.

Bioetica liberală reţine faptul că dezbaterea publică este posibilă numai dacă se caută originea autorităţii morale, dar nu în principii morale ci în simplu fapt al acordului dintre subiecţi sau dintre comunităţile umane. În această perspectivă există două principii bioetice: principiul autonomiei şi principiul beneficienţei. Primul principiu stabileşte graniţele morale fiecărei comunităţi morale iar al doilea principiu identifică conţinutul vieţii morale în evidenţierea a ceea ce este bine interpretat într-un context modern ,fă bine şi altora" şi ,ffi o persoană bună"11. Din punct de vedere juridic, persoanei îi este garantată posibilitatea de manifestare a capacităţii contractuale şi din acest motiv viaţa umană prenatală, neonatală sau terminală are un statut problematic. Mai exact, cei incapabili să-şi dea consensul devin obiecte de cercetare ale ,,agenţilor morali”, care pot să-i sacrifice în vederea realizării altui bine, precum progresul cunoştinţelor biomedicale ${ }^{12}$.

\section{Utilitarismul}

Acest curent are o prezenţă notabilă în bioetică, mai ales datorită teoriilor utilitariste ale consecinţianismului şi egalitarismului, care permit evaluarea acţiunilor oamenilor, pe baza unui criteriu al binelui şi al răului, cu imperativul moral de „,maximizare a binelui”. Se caută justificarea valorilor morale pe baza evaluării consecinţelor produse de o acţiune şi nu pe baza agentului sau a actului în sine. „Calculul utilului” ca bunăstare trebuie să ia în considerare, în mod

${ }^{10}$ Mircea Gelu Buta, Iulia Alexandra Buta, Bioetica între mărturisire şi secularizare, Cluj- Napoca, Renaşterea, 2008, p. 79-80.

${ }^{11}$ Alastair V. Campbell, Bioethics the basics, New York, Routledge, 2013, pp. 32-38.

${ }^{12}$ Maria Aluaş, Bioetica în dezbaterea contemporană. Istorie şi interpretări, în „Studia Universitatis Babeş-Bolyai-Bioethica”, nr. 1, 2011, ianuarie- iunie, pp. 45-46. 
egal interesele fiecărui individ şi să maximizeze interesele tuturor indivizilor implicaţi $1^{13}$. Pentru utilitarismul egalitarist principiul de considerare egală a intereselor presupune nediscriminarea între interese egale ale diferiţilor indivizi, dincolo de apartenenţa lor la o specie. Recunoaşterea dreptului de a nu suferi nu echivalează cu recunoaşterea dreptului de a trăi. Dreptul de a nu suferi în mod inutil are ca finalitate obligaţia de a suprima viaţa celui care suferă. Unica limită pentru nesuprimarea vieţii este preferinţa de a trăi a celui ce suferă, în cazul în care voinţa acestuia nu contrastează cu preferinţele altora. Oricum, un individ auto-conştient dacă îşi auto-evaluează negativ viaţa şi consideră că trebuie să moară atunci dorinţa sa trebuie respectată ${ }^{14}$. Într-un final etica utilitaristă înlocuieşte conceptul de „,Sacralitate a vieţii”, cu cel de ,calitate a vieţii” ${ }^{15}$, conform căruia un individ, pentru a avea statutul de persoană, trebuie să îndeplinească anumite standarde de calitate a vieţii.

\section{Materialismul}

Prin emanciparea biologiei în secolele XVIII-XIX, s-a încercat o explicaţie asupra originii şi funcţiilor vieţii în afara supoziţiilor metafizice şi teologice. Modelul materialist sau modelul sociobiologic propune o etică descriptivă conform căreia în evoluţia ei societatea elaborează şi modifică norme şi valori. În această abordare deosebirile dintre natura umană şi cea animală sunt estompate foarte mult, psihicul uman nefiind considerat radical diferit de cel animal ${ }^{16}$. Acesta este, de exemplu, şi unul din argumentele suprimării embrionului uman încă din primele stadii de dezvoltare. În acest sens dr. James Watson, câştigător al premiului Nobel, susţinea că nici un

${ }^{13}$ Solomon David, Christian bioethics, secular bioethics, and the claim to cultural authority, în „Christian Bioethics”, 2005, 11 (3), pp. 349-350.

${ }^{14}$ Jonathan Baron, Against Bioethics, Cambridge, MIT Press, 2006, pp. 25-43.

${ }^{15}$ Daniel M. Hausman, Valuing Health Well-Being, Freedom and Suffering, Oxford, Oxford University Press, 2015, pp. 105-119.

${ }^{16}$ Solomon David, op. cit., pp. 351-353. 
nou-născut nu ar trebui să fie declarant viu până când nu trece câteva teste referitoare la moştenirea sa genetică: „Dacă un copil nu a fost declarat viu până la trei zile după naştere, atunci fiecărui părinte ar trebui să i se permită să ia decizia de a lăsa copilul să moară, salvându-1 astfel de mizerie şi suferinţă" ${ }^{17}$.

\section{Pastoraţie şi misiune în bioetica ortodoxă contemporană}

Bioetica creştină poate fi definită ca întâlnirea armonioasă dintre competenţa medicală, iubirea jertfelnică şi revelaţia creştină. Fiind o disciplină a moralei creştine aplicate, ea cercetează şi emite norme morale în concordanţă cu Sfânta Scriptură şi învăţăturile Sfinţilor Părinţi pentru a păstra integritatea anatomică şi spirituală a fiinţei umane şi pentru a fundamenta moral actul medical şi deciziile necesare în practica şi cercetarea biotehnologică ${ }^{18}$.

Privite din perspectiva unei abordări eminamente ortodoxe, între bioetica laică şi cea creştină nu poate exista o împăcare. Ele sunt studiate şi analizate ca două ştiinţe distincte pentru ca deciziile conştiinţei să opereze în cunoştinţă de cauză. Dacă bioetica laică cercetează şi scormoneşte trupurile oamenilor ca un proces lipsit de perspectivă, bioetica creştină poate fi asimilată unui proces permanent de apărare a minunatei fiinţe umane.

Teologia ortodoxă pune la îndemâna bioeticianului un sistem de valori divino-umane care îl ajută să înainteze eficient din punct de vedere moral. Hristos este Logosul Întrupat Atotproniator al universului iar legile guvernatoare izvorăsc din persoana Lui. Biosul, viul este în mâna Lui proniatoare şi de aceea deciziile asupra vieţii

${ }^{17}$ Norman L. Geisler, Christian Ethics-Options and Issues, Michigan, Baker Book House, 1989, apud Natalia Vlas, Bioetica şi perspectiva creştină, în „Perspective”, nr. 8, 2007, pp. 10-11, nota 33.

${ }^{18}$ George Istodor, Bioetica creştină şi bioetica seculară: complementaritate sau antagonism?, în Mircea Gelu Buta (coord.), „Medicii şi Biserica”, vol. VIII, Cluj-Napoca, Renaşterea, 2010, p. 287. 
nu se pot lua fără a-L chema pe El ${ }^{19}$. Invăţătura creştină aşează la temeliile bioeticii valorile esenţiale revelate, practicate între creştini şi care îl transformă duhovniceşte pe om, depăşind accentuarea materialismului şi importanţa exagerată a trupului, a vieţii terestre şi a schimbărilor exterioare. Pastoraţia şi valenţele bioeticii creştinortodoxe au ca accente predominante următoarele abordări:

„Prezenţa lui Dumnezeu” în această lume, în persoana şi în viaţa umană, este o existenţă plenară, concretă şi definitorie, fiind reper pentru întreaga creaţie. De cunoaşterea acestei prezenţe depinde instaurarea raporturilor de credinţă dintre om şi Dumnezeu ${ }^{20}$, dar şi dintre persoană şi creaţie. Este important de menţionat faptul că numai o bioetică întemeiată pe experimentarea unui Dumnezeu transcendent poate oferi o morală cu un profund conţinut creştin ${ }^{21}$. Afirmarea prezenţei elementului divin în viaţa persoanei umple existenţa de sens prin raportare la transcendent.

„Viaţa umană” cuprinde în sine nu numai latura sa biologică ci şi dimensiunea duhovnicească, cele două realităţi fiind inseparabile. Misiunea bioeticii creştine, din acest punct de vedere, este acela de a promova o atitudine de preţuire şi ocrotire a vieţii umane, pentru că scopul ei ultim este îndumnezeirea. În acest sens, ,bioetica este iubirea vieţii".

„Omul-persoană” este subiectul bioeticii creştine pentru că el însuşi este subiectul relaţiilor cu transcendentul dar şi cu celelalte persoane cu care intră în contact. Biserica are obligaţia şi misiunea de a pune la dispoziţia omului mijloacele spirituale, de a urmări aplicarea

${ }^{19}$ Pavel Chirilă, Lucian Gavrilă, Cristina Gavrilovici, Lucian Băndoiu, Pricipii de bioetică. O abordare ortodoxă, Bucureşti, Edit. Christiana, 2008, pp. 21-22. ${ }^{20}$ James F. Childress, Religion, Theology and Bioethics, în Franklin G. Miller, John C. Fletcher, James M. Humber (editors), „Bioethics. Interdisciplinary Perspective", New Jersey, Humana Press, 2007, pp. 46-50.

${ }^{21}$ Engelhardt H. Tristram JR., Moral pluralism, the crisis of secular bioethics, and the divisive character of christian bioethics: taking the culture wars seriously, în „Christian Bioethics”, 2009, 15 (3), p. 240. 
normelor de morală în cadrul social în care omul convieţuieşte cu semenii săi, vizând în mod special dimensiunea fundamentală a bioeticii $^{22}$. E imperios necesar ca problemele bioetice actuale să fie permanent actualizate şi dezbătute în cadrul Bisericii, prin reafirmarea normelor morale, practicate în cadrul comunităţilor creştine.

„Dimensiunea socială” este un alt aspect important pe care Biserica trebuie să-1 aibă în vedere atunci când este vorba de domeniu bioeticii, mai ales pentru faptul că ea cuprinde arii din ce în ce mai extinse: de la liberalizarea avortului la căsătoriile dintre persoane de acelaşi sex, de la experienţele pe embrioni la organismele modificate genetic, de la ecologie la eutanasie. Biotehnologiile actuale reeditează un mai vechi conflict dintre credinţă şi ştiinţă. Modificarea radicală a imaginii despre lume prin intermediul ştiinţei moderne nu poate fi înţeleasă fără punerea acestui fapt în contextul procesului de secularizare $^{23}$. In aceste condiţii, Bisericii îi revine responsabilitatea de a arăta că raportul dintre credinţă şi ştiinţă în ceea ce priveşte orizontul bioeticii este cel redat de Mântuitorul: „Da-ţi cezarului ce este al cezarului şi ce este al lui Dumnezeu, lui Dumnezeu" (Matei 22, 21).

„,Dezbaterea publică bioetică” reprezintă fără îndoială şi ea o formă concretă de pastoraţie. În general, dezbaterile bioetice de tip public sunt aproape în totalitate seculare şi urmăresc eliminarea convingerilor morale creştine şi percepţiilor spirituale din viaţa morală publică. Creştinii sunt, de cele mai multe ori, puşi în situaţia să refuleze angajamentele lor cele mai profunde. Creştinismul trebuie să se opună culturii generale seculare actuale tocmai pentru că el posedă o percepţie superioară asupra modelului moral bioetic prin intermediul unei viziuni corecte asupra omului şi lumii. Conform principiului care

\footnotetext{
${ }^{22}$ Idem, Sin and bioethic: why a liturgical anthropology is foundational, în „Christian Bioethics”, 2005, 11 (3), pp. 221-227.

${ }^{23}$ Radu Preda, Tradiţie şi modernitate în dezbatere bioetică actuală. Consideraţii social-teologice, în Mircea Gelu Buta (coord.), „Medicii şi Biserica”, vol. VIII, Cluj-Napoca, Renaşterea, 2010, pp. 202-203.
} 
spune ca nici o politică publică nu poate fi neutră ${ }^{24}$, toţi creştinii au obligaţia morală de a susţine idei şi argumente bioetice creştine în cadrul forumului public şi de a impregna cultura modernă, printr-o invitaţie la convertirea mentalităţilor secularizante ${ }^{25}$.

\section{Concluzii}

În articolul de faţă am încercat să radiografiez în mod succint şi interdisciplinar cele mai importante aspecte pe care le utilizează bioetica seculară în definirea metodelor şi conţinutului său. Scopul acestei analize a fost acela de a identifica metodele pastorale cele mai eficiente în propovăduirea bioeticii creştine, o bioetică a iubirii şi compasiunii în care viaţa umană biologică şi spirituală are de partea ei o morală creştină capabilă de a răspunde noilor provocări biotehnologice.

Omul se mântuieşte prin Hristos dar şi prin aproapele său, aspect subliniat tot mai pregnant de domeniul bioeticii, unde persoana depinde definitoriu de cel de lângă ea. Aici, în cadrul acestei relaţii, se defineşte până la urmă relaţia bioeticii cu credinţa, deoarece de calitatea raportării la transcendent va depinde atitudinea noastră a tuturor faţă de viaţă, în cadrul căreia se manifestă Însuşi Dumnezeu, Viaţa noastră.

${ }^{24}$ Søren Holm, Policy-Making in Pluralistic Societies, în Bonnie Steinbock (editor) „The Oxford Handbook of Bioethics”, Oxford, Oxford University Press, 2007, p. 155.

${ }^{25}$ Mark J. Cherry, Bioetica ceştină şi forumul public: De ce trebuie să se implice creştinii în dezbaterile morale publice, în „Revista Română de Bioetică”, vol. VII, nr. 1, ianuarie-martie, 2009, pp. 47-49. 
